\section{A conversation with Aled Edwards}

\section{By Amy Donner, Senior Editor}

As the Structural Genomics Consortium enters its second decade, the challenge has shifted from showing that its model of providing open access to biological data is sustainable to expanding intellectual and geographic reach. Thus, the consortium now is looking to engage clinical scientists and add a site in South America.

The SGC is a not-for-profit public-private partnership (PPP) that produces 3D structures of biomedically relevant proteins as well as chemical tools that enable drug discovery. Outputs from the consortium are placed in the public domain without IP restrictions.

When the SGC was formed 10 years ago by GlaxoSmithKline plc, the Wellcome Trust and Canadian funders, there were doubts about the attractiveness and sustainability of the model because of its no-IP policy.

The SGC received an initial investment of $\$ 95$ million. CEO Aled Edwards was tasked with building a partnership that could deliver structures for 350 new human proteins by July 2007 and hiring team leaders and staff for sites in Oxford and Toronto.

Edwards is a professor of medical research at the University of Toronto and a visiting professor of chemical biology at the University of Oxford.

To date, the SGC has produced structures for over 1,500 proteins-about $15 \%$ of the human proteome-and has ongoing collaborations with more than 300 groups.

The consortium has expanded from the original 6 founding organizations to a total of 13 members, including 9 pharma companies.

SciBX talked with Edwards about how the consortium has continued to grow and evolve and about the future for open-access partnerships in biomedical research.

SciBX: What was the motivation for founding the SGC?

Al Edwards: Rob Cooke and others at GSK came up with the idea to pool resources to solve the protein structures that each company was working on individually. Because the Wellcome Trust was involved in building a synchrotron and was motivated to seed research activity around it, there was a nexus of interest from pharma and Wellcome to build a SNP-like consortium [the Single Nucleotide Polymorphism Consortium] for protein structures in Oxford.
SciBX: What were the early days like?

$A E:$ In 2003, wewere in hunker-down mode. Therewere 2 of us, emptylabsanda $\$ 100$ million check. Our goal was to solve 350 human protein structures by mid-2007. And we had to solve them from a list provided by the funders. There were a lot of doubts that we could meet our goal. We solved 465 structures.

In 2007, we proposed structures as our goal again, this time committing to solve 650 with some membrane proteins. By 2011, we had solved 692 structures.

SciBX: What was the initial perception of the SGC and its open-access research model?

$A E$ : One bias from the academic world was that the effort constituted a nonscience-driven factory that was simply taking money away from the funding base. A second bias was that we were doing industry's business with the public purse. This bias was mitigated somewhat by the involvement of respected organizations like the Canadian funders and the Wellcome Trust.

Pharmaceutical companies had different biases. First, and one that remains today, is that consortia involving academics cannot be successful. The second was that their internal structural biologists could tackle any problem without help. This, of course, was true. The third view was that any donation to the public good only served to support their competitors-the free-rider argument. Of course, there is some truth to this as well.

SciBX: Has this perception changed among academia?

$A E$ : Ten years later, there is more acceptance of the idea that this project serves the public good. We have hundreds of collaborators in academia and have published with 150 different institutions in the past 3 years alone. Our structures have a reputation of high quality, and our work is known for being reproducible. So yes, I believe it has changed.

\section{SciBX: And among pharma?}

$A E$ : Yes, I think the perception changed because the SGC as a precompetitive consortium delivers what it says it will, and produces high-quality, reproducible science. The perception change has also been helped by the ever-increasing squeeze on research dollars. Companies can spend $\$ 1$ to get $\$ 1$ of research internally or spend $\$ 1$ to get $\$ 10$ of research or more in the SGC and its collaborative network.

Leveraged funding, huge academic network, no TTOs [technology transfer offices] in the way, pioneering science, reproducible results and, soon, open access to patient-derived cells-it makes sense to many companies. 
SciBX: How did the SGC get interested in chemical probes?

$A E$ : In 2004, we started to build chemistry capabilities. We knew then that we ultimately wanted to make inhibitors, but we were only funded for structures. We knew that having a small molecule that bound a protein could improve the probability of getting crystals and showed this using hundreds of examples with the thermal shift assay. ${ }^{1}$

Thus, we made the argument that we needed to build small molecule libraries in order to identify small molecules that stabilized proteins and increased the efficiency of solving structures. And so we were into chemical biology.

In 2009, we published our open-access model for chemical probes. ${ }^{2}$ GSK, led by Tim Willson and others, took the plunge and engaged with us to make tool compounds against epigenetic targets and put them in the public domain. This was an enormous inflection point.

Fast forward to 2014-we have many chemical libraries in house, and we occasionally put out a chemical probe. The consortium is also helping to raise the bar for how a chemical probe is defined and validated. With industry's help, we're making high-quality molecules. This is a significant contribution. Every chemical probe costs over $\$ 2$ million to make, and after we make them, we simply give them away.

In 2013 alone, over 1,500 samples were distributed. The success of this project, which focuses on proteins implicated in epigenetic signaling, has encouraged us to expand the remit. Thus-again with the leadership of

"I think in the coming years,
you are going to see greater
scrutiny of PPPs in terms of
value created. And by value
I mean scientific, economic
and social. Perhaps when
those analyses are done,
the advantages of the open-
access model will become
more starkly apparent."
-Aled Edwards,
Structural Genomics Consortium

SciBX: How do you compare the productivity of the SGC to other PPPs?

$A E$ : There are no good measures for this. To my knowledge, PPPs set objectives but don't advertise them, or they set fuzzy objectives. They are rarely held to account. In some cases, the partnership rather than the outcome is viewed as the end goal.

At the SGC, if we don't meet our objectives, people lose their jobs. There is a greater sense of urgency for us, and a four- to five-year funding cycle keeps the fear of failure real.

But meeting our milestones is not enough. The unwritten objectives have included GSK-we are soon launching a project to generate chemical probes to protein kinases implicated in the regulation of epigenetics and also RNA biology. ${ }^{3}$

This project will involve a new laboratory at the University of Campinas in Brazil, and we are excited that the open-access model is expanding beyond Canada and Europe.

SciBX: What will the next phase look like for the SGC?

$A E$ : We have noticed that when the tools we generate are used by clinicians in patient-derived samples, there is much more rapid uptake of the probes by other academic scientists and much more interest generated in industry. So the path is obvious-continue to make tools, but organize networks of clinical institutions that agree to use the tools in patient-derived samples and make the data available without restriction.

We have already established very focused collaborations, knowledgebased collaborations, with three hospitals. Making sure that these are successful and expanding the number of collaborators is our vision for the next five years.

SciBX: What makes the SGC unique?

$A E$ : I think we are unique from an organizational point of view. To my knowledge, no other PPP of this scale has an explicit no-IP policy. We are also more like a company within academia. creating a culture of transparency in sharing our data and the impact of our papers. I'm starting to hear about the need for job creation, but no one will give me target numbers.

SciBX: What are the biggest challenges for the open-access model?

$A E$ : Balancing the expectations of the various funders is the hardest aspect of what I do. Academics and public-sector funders respect papers, and companies care about the impact, as well as quantitative metrics to ensure that there is no mission drift. There is always some internal tension.

Maintaining public funding is a humongous challenge. Our only public funders have been the Canadian and Ontario governments. And we increasingly face the question-if industry sees the value in funding the SGC, why are we needed? Of course, when I go to industry, the question is why should we fund the SGC if the project generates basic science. Therein lies the challenge.

Of course, the real reason to have both sectors supporting us goes beyond economics. The involvement of the public sector assures our collaborators that our mission is to serve the public good-and this has allowed us to collaborate with anybody without involving TTOs and without the need for MTAs. If we were funded exclusively by pharma, I am sure that many scientists would not collaborate with us.

If the private sector were absent, then there would be a natural tendency to slow down and chase some of the fascinating scientific 


\section{ANALYSIS}

\section{TRANSLATIONAL NOTES}

stories we have uncovered. Their most important contribution is their expertise-access to their medicinal chemists is priceless.

SciBX: There is an abundance of PPPs now. Why do you think the IP-free model for open innovation remains rare?

$A E$ : It remains hard for people to wrap their heads around the fact that the misuse of patents and the opportunity cost of filing patents at the early stages of any business can have a detrimental effect on innovation. And there is also the lottery ticket mentality, where on rare occasions, one can get lucky and generate a result of enormous commercial benefit.

I think in the coming years, you are going to see greater scrutiny of PPPs in terms of value created. And by value I mean scientific, economic and social. Perhaps when those analyses are done, the advantages of the open-access model will become more starkly apparent.

SciBX: After 10 years, what are the biggest benefits you have seen come from the open-access research model?

$A E$ : This is an interesting question. I could point to the dozens of high-profile papers that have emerged from our work, but to be honest if you took the funding we received and distributed it among a dozen top scientists, I'm sure that they'd publish good papers too.

I think the real benefits come from the fact that on top of the papers we publish, we make enabling tools available. And the unrestricted availability of these tools has proven a powerful accelerant to science. Second, the open-access framework and the willingness to share our output is what allows us to focus resources on areas of the proteome that would be very difficult to fund in any other way.

SciBX: Thank you very much for your time.

Donner, A. SciBX 7(21); doi:10.1038/scibx.2014.604

Published online May 29, 2014

\section{REFERENCES}

1. Vedadi, M. et al. Proc. Natl. Acad. Sci. USA 103, 15835-15840 (2006)

2. Edwards, A.M. et al. Nat. Chem. Biol. 5, 436-440 (2009)

3. Knapp, S. et al. Nat. Chem. Biol. 9, 3-6 (2013)

COMPANIES AND INSTITUTIONS MENTIONED

GlaxoSmithKline plc (LSE:GSK; NYSE:GSK), London, U.K.

Structural Genomics Consortium, Oxford, U.K.

University of Campinas, São Paulo, Brazil

University of Toronto, Toronto, Ontario, Canada

University of Oxford, Oxford, U.K.

Wellcome Trust, London, U.K. 